\title{
105. A Preliminary Note on an Aberrant Autosome (Group 13-15) in a Male Child and in his Father
}

\author{
By Hatao Kato,*) Tatsuo Omura, ${ }^{* *)}$ Shigeo Tabata, ${ }^{* * *}$ and \\ Sajiro MAKINO ${ }^{* * * *)}$ \\ (Comm. by Yoshimaro TanaKa, M.J.A., June 12, 1965)
}

In the course of a chromosome survey in human subjects with sexual anomalies, a child with undescended testes (cryptorchism) and his father, apparently normal, were found to possess an aberrant autosome in group 13-15. The cases to be described here seem to be the first recorded ones in the Japanese population. The present paper reports the preliminary results of karyotype analyses in the above subjects.

Clinical records: Personal interview with the father of the patient has revealed that all paternal living sibs are married and each has two or three offspring, respectively, and that no familial or congenital diseases occurred in the relatives other than the propositus concerned here.

The propositus (Fig. 1) is the first and only child, aged 18 months, born to his parents who are physically and mentally normal. The

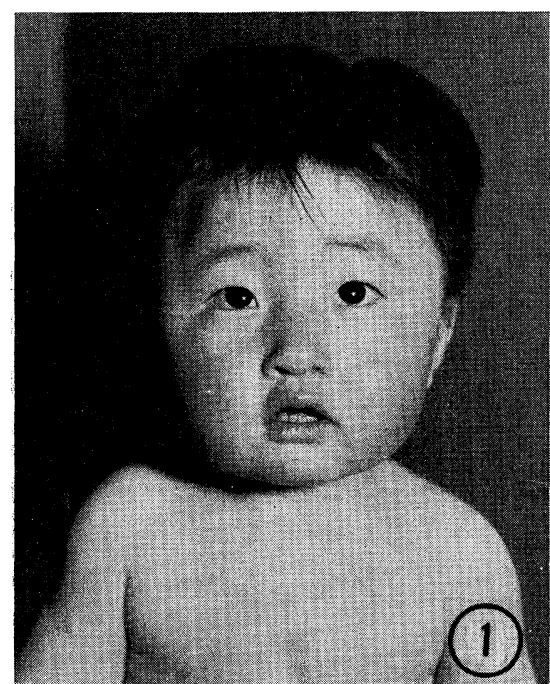

Fig. 1. Propositus, 18 months of age.

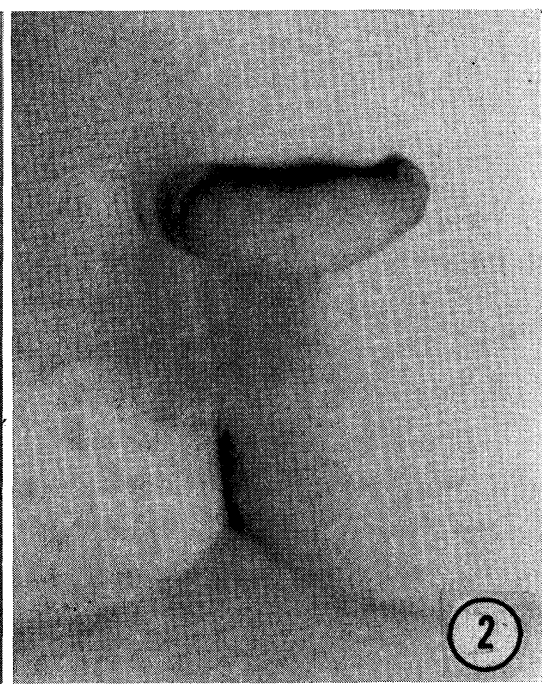

Fig. 2. External genitalia of the propositus.

*) Division of Biology, National Institute of Radiological Science, Chiba.

**) Department of Biology, Faculty of Science, Okayama University, Okayama.

***) Section of Urology, Hokushin Hospital, Sapporo.

****) Zoological Institute, Faculty of Science, Hokkaido University, Sapporo. 
father's and mother's ages at the birth of propositus were 27 and 25 years, respectively. Clinically the propositus was found to have undescended testes, though not by operation (Fig. 2), together with congenital dislocation of the hip. His mental and some other physical developmental features appeared normal for his age, showing no sign of Down's syndrome.

Chromosome analysis: Blood chromosomes were exclusively used for study in both the propositus and his parents. Table I provides the results of chromosome counts.

Table I. Chromosome constitutions in the propositus and his parents

\begin{tabular}{lrrrrrrrr}
\hline \multirow{2}{*}{ Case } & \multicolumn{4}{c}{ Chromosome counts } & No. of cells & $\begin{array}{c}\text { Modal chr. } \\
\text { obs. }\end{array}$ \\
\cline { 2 - 5 } & 43 & 44 & 45 & 46 & 47 & 48 & & no. \\
\hline Propositus & & & 1 & 50 & 1 & & 52 & 46 \\
Father & & & 2 & 48 & & & 50 & 46 \\
Mother & 1 & & & 35 & & & 36 & 46 \\
\hline
\end{tabular}

Fig. 3 is a karyotype analysis in the propositus. Precise examinations revealed a normal diploid number, 46, in many metaphasic cells. In every intact cell analysed, five acrocentric members belonging to group 13-15 fell within normal limits of variation, leaving one chromosome which was characterized by an unusually enlarged short arm. The aberrant chromosome is in all probability a member of the no. 15th pair, and very prominent in appearance, being very easily distinguishable from the other members of group 13-15 on account of its extra short arm. The unusually enlarged short arm carried a slight constriction, being slightly smaller in size than that of the long arm of acrocentric chromosomes belonging to group 21-22. All metaphasic cells examined so far showed this aberrant chromosome without exception. The remaining elements were apparently normal; there was no indication in them of signs of morphological anomaly at all.

The karyotype of the patient's father showed an aberrant chromosome morphologically identical with that of his son (Fig. 4); the other elements were normal in general appearance. The mother was found to have 46 chromosomes of an apparently normal female complement (Fig. 5).

Remarks: Patients with undescended testes have been reported to have an apparently normal karyotype (cf. Makino 1964). The present investigation has revealed that an acrocentric chromosome belonging to group $13-15$ has an unusually enlarged short arm in both the propositus and his father. Evidently the father transmitted the aberrant chromosome to his son without any shift. Hetero- 


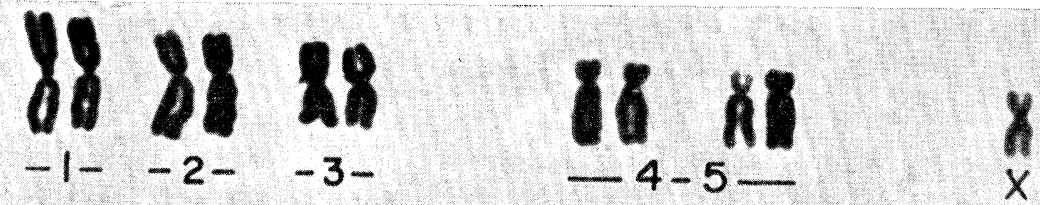

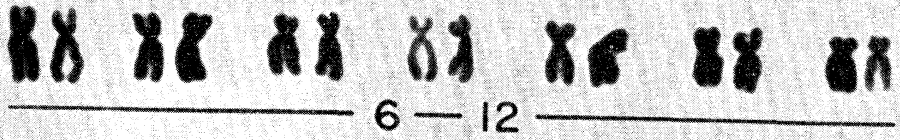

An on ad $x \times$ h

$-13-15-\quad-16-18$

$\begin{array}{ccc}x * x & A & A \alpha \\ -19-20- & -21-22-\end{array}$

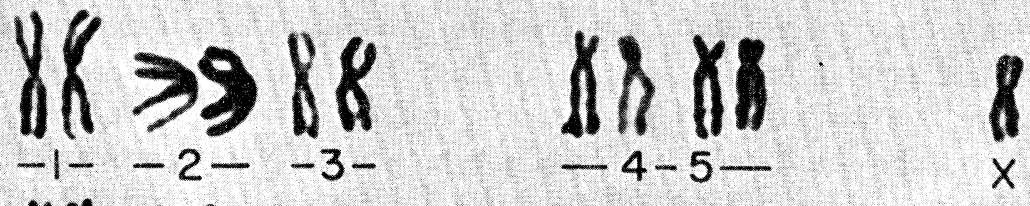

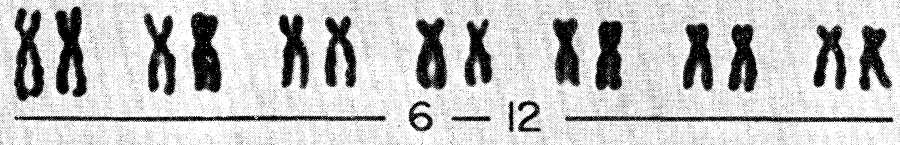

10 $11 \ln _{13-15} n x^{\prime} \quad \frac{x x}{16-18}$

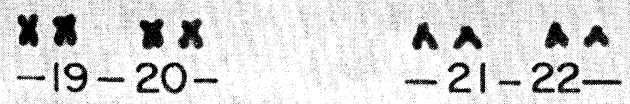

ligio is

$-1--2--3-$
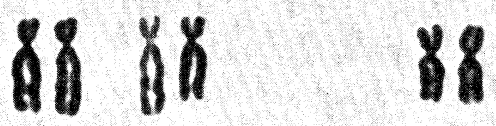

$\frac{687888}{\text { an } 18}$

$-4-5-$

$x \times$

$-13-15$

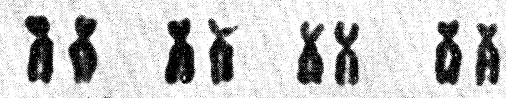
$6-12$

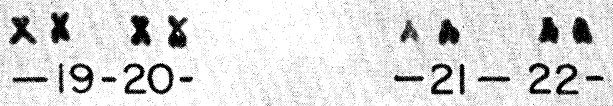

Figs. 3-5. Karyotypes of the propositus and his parents. 3: karyotype of the propositus. 4: karyotype of the patient's father. The aberrant chromosome is indicated by an arrow. 5: karyotype of the patient's mother with a normal female complement. 
morphism of a similar nature in an autosomal pair was found to occur in some vertebrates, for example in the tree frog (Seto and Makino 1964).

The general interpretation for the origin of the aberrant chromosome may likely be that an extra chromosomal piece has translocated to the short arm of a chromosome from another element which is not identified in this study. A pericentric inversion in the abnormal chromosome seems an unlikely interpretation, since its long arm showed no visible decrease or change in size. In the present situation, it is impossible to detect the chromosome from which the extra piece has been derived.

It has been reported that certain morphological variations occur in acrocentric chromosomes as well as in the chromosomes no. 16 (cf. Makino 1964). A number of reports on related features tended to associate apparently minor chromosomal abnormalities with pathological states (Moorhead et al. 1961, Schmid 1962, Sasaki et al. 1963). However, variations of a similar nature have also been occasionally found in the karyotypes of phenotypically normal human beings. Chandra and Hungerford (1963) reported an unusually satellited submetacentric chromosome in a healthy 21-year-old girl, as well as in her father, apparently normal. Jacobs et al. (1964) observed anomalous acrocentric chromosomes in groups $13-15$ and $21-22$ in several elderly subjects who were randomly chosen from the population.

There are a number of Down's syndrome cases in which the extra chromosome, no. 21, has translocated to another autosome. Shaw (1962) undertook a chromosome study in several familial cases of Down's syndrome, in one of which the translocation occurred for three successive generations. Very recently Sergovich et al. (1964) reported two atypical Down's syndrome cases with unusual, clinical and chromosomal features, one of which carries an aberrant autosome in group 13-15. Other members of that family possessed a normal chromosome complement. The aberrant chromosome is morphologically identical with that observed in the present study. There is no sibling with Down's syndrome in the familial history of the present case.

In fine, it may be quite probable that the anomalous acrocentric chromosome with an enlarged short arm in this case is, like the increased length of the human $\mathrm{Y}$ chromosome, heritable and that the aberrant chromosome is not always associated with specific phenotypic abnormality. In general, cryptorchism is associated with no specific abnormality, an apparently normal complement having been reported in most cases (Makino 1964). There remain at the present time many questions as to the origin and nature of the aberrant chromo- 
some for future cytogenetical studies on sibs of this family.

Cordial thanks are due to Drs. Motomichi Sasaki, Akio A. Awa, Takeo Honda, and Nobuo Takagi for their friendly assistance and invaluable criticism.

\section{References}

Chandra, H. S., and D. A. Hungerford (1963): Cytogenetics, 2, 34.

Jacobs, P. A., M. Brunton, and W. M. Court Brown (1964): Ann. Hum. Genet., Lond., 27, 353.

Makino, S. (1964): Cytologia, 29 (Part II), 125.

Moorhead, P. S., P. C. Nowell, W. J. Mellman, D. M. Battips, and D. A. Hungerford (1960): Exp. Cell Res., 20, 613.

Moorhead, P. S., W. J. Mellman, and C. Wenar (1961): Am. J. Human Genet., 13,32 .

Sasaki, M. S., S. Makino, and T. Kajii (1962): Proc. Japan Acad., 39, 394.

Schmid, W. (1962): Cytogenetics, 1, 199.

Seto, T., and S. Makino (1964): Proc. Japan Acad. 40, 862.

Sergovich, F. R., G. H. Valentine, M. B. Car, and H. C. Soltan (1964): J. Pediat, St. Louis, 65, 197.

Shaw, M. W. (1962): Cytogenetics, 1, 141. 